\title{
School Principals' Perceptions of Teacher Evaluation in the Arab Education System in Israel
}

\author{
Jamal Abu-Hussain \& Mohammad Essawi \\ Academic College of Education Al-Qasemi, Israel \\ Correspondence: Mohammad Essawi, Academic College of Education Al-Qasemi, Israel.
}

Received: October 25, 2013 Accepted: November 18, 2013 Online Published: January 24, 2014

doi:10.11114/jets.v2i2.255 URL: http://dx.doi.org/10.11114/jets.v2i2.255

\begin{abstract}
The objective of this research is to examine how principals of Arab schools view the evaluation of teachers and to determine whether and to what extent their perceptions of teacher evaluation differ. The Arab educational system in Israel is an integral part of the general educational system. For the most part it is run by Jewish administrators. Fundamental decisions are determined by officials who are not Arabs, despite the fact that the Arab citizens of Israel possess unique national and cultural characteristics. This systemic control has prevented Arabs in Israel from controlling the objectives of education or from shaping and directing the Arab educational system according to the collective interests of the Arab public. The findings of the study can contribute to research knowledge about school principals and can help in making decisions regarding how to introduce, adapt and make more intelligent use of teacher evaluation. School principals' perceptions of teacher evaluation are an expression of their leadership style. These perceptions also have an impact upon patterns of using teacher evaluation. Principals can view evaluation as part of their administrative functions or as part of their pedagogical and leadership roles. Thus it can be assumed successful use of teacher evaluation is also related to the principals' perceptions of this evaluation. The way in which principals view teacher evaluation is defined by how they see the objectives of this evaluation. To what extent do they see teacher evaluation as a systematic means for determining teacher compensation, promotions and continued employment? Alternatively, do they see it as a way to empower teachers by helping them develop and improve their teaching performance? The data were collected from 100 school principals. The results indicate that most of the principals saw the evaluation process as transformational and constructive. In their view, the objective of teacher evaluation is to help teachers improve their work. The principals who did not participate in the in-service training saw teacher evaluation as a means of exercising control, offering compensation and demonstrating authority.
\end{abstract}

Keywords: teacher evaluation, school principals

\section{Introduction and Review of Literature}

The objective of this research is to examine how principals of Arab schools view the evaluation of teachers and to determine whether and to what extent their perceptions of teacher evaluation differ. The findings of the study can contribute to existing research knowledge about school principals. These principals are the educational and pedagogical leaders charged with guiding the Arab educational system into the $21^{\text {st }}$ century and helping it cope with the many challenges it faces, in particular the evaluation of teachers and the promotion of teaching and learning in the schools.

Very few studies have examined perceptions of teacher evaluation among principals of Arab schools. Hence, the findings of this study can help in deciding upon more intelligent ways to introduce, adapt and use teacher evaluation. The findings can be applied in setting Ministry of Education policies as well as on the level of the schools and the principals, who play a major role in teacher evaluation and professional development.

The Arab educational system in Israel is an integral part of the general educational system. For the most part it is run by Jewish administrators and defined as an educational system for Arabs rather than an Arab educational system. Local decisions made by low-level Arab functionaries are usually technical in nature, while the more fundamental decisions are determined by officials who are not Arabs, despite the national and cultural distinctiveness of the Arab citizens of Israel. This situation has prevented Arabs in Israel from controlling the objectives of education or from shaping and directing the Arab educational system according to the collective interests of the Arab public and has hindered any 
meaningful intervention by Arab inspectors, principals and educators in making any fundamental decisions for the system (Jabareen and Agbaria, 2010).

Recently the Ministry of Education has begun a process of decentralization throughout the system, by placing the authority for teacher evaluation in the hands of the school principals as a first step. This new approach has raised the issue of whether Arab school principals can carry out a professional and objective evaluation within a very complex reality. On the one hand, the principals are supposed to promote an organizational culture marked by required standards and transparency. They must attempt to do this within the traditional and family-oriented social and cultural reality of a minority group, a reality usually marked by appeasement and a low level of transparency (Arar, 2010). On the other hand, these principals cannot make fundamental decisions with respect to the schools they run because the Ministry of Education controls most of the essential decisions concerning Arab education.

The Ministry of Education launched a project to evaluate teachers based upon objective measures. The project was premised on the notion that if teachers and principals were actively involved, the evaluation would help improve teaching quality, promote student learning, education and well-being, and develop the teachers' professional identity. The evaluation processes were to be based upon an organizational culture centered on binding norms and ethical codes of respect, trust, fairness, reflective dialogue and partnership. Thus the evaluation would constitute an important stage in constructing a professional school community focused on improving and advancing the educational system (Beller et al., 2011).

During the 2011-2012 school year, principals in Israel began to be trained in using the teacher evaluation instrument developed by the Israeli National Authority for Measurement and Evaluation in Education (RAMA). Proper use of this instrument should help advance the primary objective of teacher evaluation - improving how teachers teach in order to promote student learning and student achievements. The results of the current study should contribute to understanding the difficulties and barriers faced by principals in the Arab educational system when evaluating teachers. The results will also help principals become more aware of their perceptions of the topic of teacher evaluation.

A basic educational assumption is that student learning cannot improve effectively over time without improving the way teachers teach (McKinsey et al., 2007). From the perspective of a principal who acts as pedagogical leader, this assumption is of decisive importance. First, the principal must devote considerable time and effort in training and advising teachers. Second, the principal must be present at all major pedagogical crossroads. Finally, the principal must enter the classrooms, observe the lessons and provide feedback to the teachers. Yet the principal's focus in education is not only direct, but rather indirect as well (Coldren \& Spillane, 2007).

\subsection{Perception of Evaluation}

Teacher evaluation is a complex concept that involves a number of measures affecting teachers and teaching. In the current study, teacher evaluation refers to assessing teachers' abilities and offering feedback on how these abilities are implemented in the classroom and to what extent they are effective (Darling-Hammond et al., 1983). Thus, teacher evaluation attempts to evaluate three major components. The first is teacher competence, which refers to a teacher's repertoire of qualifications and abilities. The second is teacher performance, which refers to what a teacher does in his/her work. This performance is dependent upon the teacher's skills, the context in which he or she acts, and the extent of his or her ability to put these various skills to use at any given point in time. The third component is teacher effectiveness, which refers to the impact of teacher performance on the students. This effectiveness is dependent not only upon competence and performance, but also on the students' responses. These three components are to a large extent the basis for the theoretical frameworks of teacher evaluation described in the literature.

Perception refers to how individuals use their senses to actively absorb, organize and interpret what is happening in their immediate and adjacent environment (Abu-Hussain \& Gonen, 2013).

In other words, the way in which an individual perceives reality affects his behavior. Perception is a major stage in the study of organizational behavior and in the analysis of the behavior of people and of groups in organizations. Many organizational processes are influenced by the ways in which people perceive their surroundings (Robbins, 2001). In organizations, decisions are usually made by people who are susceptible to diversions in their perceptions. Therefore, it is important to be aware of this and to try to prevent it as much as possible.

Two central organizational processes have a major impact on the perceptions of individuals involved in decision-making processes: employee screening and employee evaluation. Interviews are a common method used to screen those who are hired to work in an organization. Through interviews, the organization's representative can assess the candidate based on perceptions of whether the candidate is suited to the job and the organization. The way in which a candidate is perceived is subject to various cognitive deviations that are liable to distort the screening process. This immediate perception of the candidate has a major impact on the results of the interview (Robbins, 2001). 
Organizations evaluate their employees' on-the-job performance, often as part of mechanisms for promotion, salary changes and organizational changes. Usually the evaluation is carried out by the manager and is therefore liable to be influenced by the manager's perceptions of the role of the evaluation. The manner in which teacher evaluation is carried out also expresses the principal's perceptions and leadership style (Conley and Glasman, 2008). The principal may perceive of the evaluation as an administrative task, carried out for purposes of supervision, follow-up and demonstrating authority. Alternatively, he may see it as an act of pedagogical leadership and as a tool for characterizing the organizational culture with the goal of delineating educational policy towards developing the teachers' teaching skills (Mcghee \& Nelson, 2006).

Based upon the above claims, in this research principals' perceptions of teacher evaluation are defined as the way in which the principals view the objectives of the evaluation. Do they see teacher evaluation as a systematic way of determining a basis for the remuneration, promotion, transfer, salary level and continued employment of the evaluated teachers (Nevo, 1989)? Or do they see evaluation as a means of empowerment that supports teachers' professional development and improves their performance? Is it a learning experience that will motivate teachers to develop and improve their performance in the classroom in the future?

\subsection{Development of Teacher Evaluation}

In the past, teacher evaluation in the education system in Israel was technical and formal, carried out simply to fulfill an obligation and for the most part summative in nature. It was intended mainly for purposes of screening and authorization and was considered a form of educational supervision. Many educational institutions disregarded the need to evaluate teachers. In other cases, the evaluation took place in a negative climate and at a low level of trust and did not achieve its goal of improvement and development (Danielson, 2001). Yet as a result of the growing insight that teachers are the most important factor in education, the educational community began changing its perception of the role of teacher evaluation. With time, other objectives were added: transformational evaluation, intended to improve the teacher's work, and summative evaluation, intended to demonstrate the principal's authority over the teacher.

Today the trend is toward a holistic approach in teacher evaluation, both because there is no one definitive and best method for evaluating teachers and because the evaluation methods must be both transformational and summative in order to help improve teaching, serve as a focus for learning and influence teacher performance (Marshall, 2005).

Studies have shown that teachers are the factor in school that has the greatest impact on student achievements. Thus, teachers' performance in class must be evaluated systematically and meticulously so as to bring about improvement. Yet evaluation of this nature almost never takes place. Usually it is the school principal who is responsible for evaluating the teachers. To this end, the principal visits one or two classes a year for each teacher, and unless the teacher has made a serious error the principal usually gives a good evaluation. Needless to say, such an evaluation does nothing to improve teaching quality (Daley and Kim, 2010). Hence, teacher education must be improved - not in order to oversee teachers for bureaucratic purposes but rather to improve their performance, which is the key to student achievements.

Sergiovanni (2002) classifies the objectives of teacher evaluation as follows: quality control - monitoring teaching and learning in the school; professional development - helping teachers grow and develop with respect to their understanding of teaching, learning and classroom life; teacher motivation - building and fostering teacher motivation and commitment to teaching, to the school's general objectives and to its educational perspective.

Nasser-Abu Alhija (2010) notes that the shift away from traditional teacher evaluation, which is usually summative in nature, toward teacher evaluation that is transformational, empowering and enabling will be possible only when principals can offer work conditions conducive to candid discussions with teachers, carry out joint internal evaluations, create an organizational learning culture at the school and integrate teacher evaluation and teacher development into an overall plan for school improvement.

Because the principal is the leader of the school team, his leadership style is of major importance. Leadership style has an impact on numerous areas in the school, among them school climate, teacher satisfaction and classroom behavior and student response to school requirements. The principal's leadership style also indirectly affects student achievements (Fullan, 2001), the school's ability to cope with environmental changes and the school's level of effectiveness (Sergiovanni, 1990). Bass (1999) \& Sergiovanni (1990) consider transactional leadership to be pivotal and essential in preserving organizations and in maintaining and executing the routine, but not necessarily as leading to improvement. In comparison, transformational leadership provides individuals with an incentive to try to improve their performance. Transformational leadership facilitates an evaluation process that leads to empowerment, improvement and transformation, yields good results with respect to teachers' conduct, improves their organizational behavior, increases their loyalty to their place of work and elevates the level of their teaching (Sergiovanni, 1990). Studies have shown that transformational leadership is able to cope with educational challenges in a changing environment and helps the school 
successfully introduce changes. The influence of transformational leaders finds expression in the school's planning, its organizational structure and its vision and culture (Cheng, 1997; Leithwood, 1997).

Many researchers have recently noted that the school principal stands out as an effective pedagogical leader in providing support for the teachers and effectively implementing organizational processes. Such a leader provides teachers with intellectual support, offers them professional models and motivates them to improve their work. A successful pedagogical leader who is focused on learning must know what is going on in the classrooms and among the students and must make sure that the efforts of all the teachers are focused on learning (Lewis and Murphy, 2008). This principle must govern all forms of communication, data collection and assessment, staff development and the shaping of the school culture. Teachers should be evaluated based upon standards related to their performance in class, and the evaluation data must be gathered from a variety of sources in order to learn lessons that will improve teaching among teachers and learning among learners (Stiggins and Duke, 2008). From the organizational perspective, a successful pedagogical leader directs the organization, develops common goals, supervises and guides organizational performance, encourages effective communication and creates an empowering school culture in which teachers can teach and students can learn (Southworth, 2004; Leithwood et al., 2006).

Leithwood et al. (2006) note that after the quality of classroom teaching, school leadership has the second most important influence on student learning. The most successful school leaders are those who keep an open mind and are willing to learn from others. Their way of thinking within a framework of core values is flexible rather than dogmatic, and they are known for their single-mindedness (for example, in expecting high motivation, commitment, learning and achievement from their teaching staff), their resilience and their optimism.

Today school principals have a more complex, responsible and demanding job than in the past. With time, their areas of responsibility have expanded and the pressures of their work have grown. The many activities and great energy characterizing the work of school principals are backed by the values that have contributed to their vision and from which their passion for their work derives. These values nourish them and enable them to go on with their work, serve as a compass for them to go forward and instill their everyday activities with meaning (Southworth, 2009).

The school principal is the main educational figure at the school. In this capacity, the principal must evaluate teachers and act to advance teaching and learning at the school (Guterman, 2010). Teacher evaluation is perceived as one of the central means of improving teaching among teachers, learning among students and school effectiveness (Leithwood et al., 2007).

The findings of a study by Kurland (2010) of school principals in Israel reveal a gap between the principals' perception of evaluation and the evaluation actions they report on taking. The principals see the role of evaluation as important and contributing to teachers' professional development, the quality of teaching and the students' achievements. Yet the findings also show that for the most part the evaluation is not professional. It is one-directional, and the only evidence of teacher performance is usually collected by the principals. Principals tend to use more latent and manipulative forms of evaluation and fewer cooperative, consistent and systematic processes. An analysis of principals' reported evaluations shows that their leadership is mainly bureaucratic and hierarchical in that it makes use of evaluation as a means of control and compensation and as a show of authority. To a much lesser extent principals demonstrate transformational and pedagogic leadership that uses evaluation processes to help teachers improve their teaching and to support their professional development.

In a study of ten elementary school principals in the Arab educational system in Israel, Arar (2010) reveals the organizational barriers in government institutions, the Ministry of Education controls most of the essential decisions concerning Arab education and the social and cultural barriers, appeasement and a low level of transparency in Arab society as mentioned above. These barriers put constraints on the principals in their evaluation of teachers and make it difficult for them to implement a systematic and thorough assessment. He also notes that most of the principals tended to place more emphasis on the summative role of the evaluation and less on its transformational role.

The perceptions of school principals in general, and their perceptions of teacher evaluation in particular, have an impact on the ways they conduct themselves in the school and on their patterns of using teacher evaluation. It can be assumed that school principals' successful use of teacher evaluation is also linked to their perceptions. Hence, the current study seeks to examine the perceptions of school principals regarding teacher evaluation and to determine whether and to what extent these perceptions vary among principals in the Arab educational system in Israel.

\section{Methodology}

\subsection{Research Questions}

How do principals of Arab schools perceive teacher evaluation?

Do these perceptions vary among principals in the Arab educational system in Israel, and if so, to what extent? 


\subsection{Research Hypotheses}

1) The research findings will show that most of the principals perceive of teacher evaluation as transformational evaluation.

2) The perceptions of teacher evaluation will differ between those principals who received in-service training on this topic and those who did not have such training.

3) The findings will show that principals who did not receive in-service training perceive of teacher evaluation as summative, while those who did receive such training perceive of such evaluation as transformational.

\subsection{Study Population and Sample}

The study population includes a group of elementary, middle school and high school principals from the Arab education system in the Ministry of Education. This system includes 399 elementary schools, 63 middle schools and 204 high schools, for a total of 666 schools.

The sample was a stratified random sample. For the quantitative analysis, 90 principals of elementary, middle and high schools were chosen randomly to complete the questionnaire.

Table 1. Distribution of research population by gender (numbers and percentages)

\begin{tabular}{ccc}
\hline Gender & Number & \% Percentage \\
\hline Male & 68 & 79.1 \\
Female & 18 & 20.9 \\
Total & $\mathbf{8 6}$ & $\mathbf{1 0 0}$ \\
\hline
\end{tabular}

Table 2. Distribution of research population according to type of school

\begin{tabular}{ccc}
\hline Type of School & Number of Principals & \% Percentage \\
\hline Elementary School & 51 & 59.3 \\
Middle School & 22 & 25.6 \\
High School & 13 & 15.1 \\
Total & $\mathbf{8 6}$ & $\mathbf{1 0 0}$ \\
\hline
\end{tabular}

The qualitative part of the study focused on those principals who had received in-service training on the topic of evaluating teacher performance. Ten of these principals were chosen.

\subsection{Research Tools}

As noted, both quantitative and qualitative tools were used to collect the data. We chose an approach that combined these two methodologies to reinforce the validity of the research findings. This approach allows for a certain degree of objectivity on the one hand, while on the other hand makes it possible to analyze educational perceptions from various perspectives. This approach also helps in balancing the disadvantages of each method (Alpert, 2010).

A questionnaire was constructed for the purpose of the study. The questionnaire examined the principals' perceptions of teacher evaluation at school in two different areas (perceptions of teacher evaluation as summative and perceptions of teacher evaluation as transformational).

\subsection{Questionnaire Validity}

The first investigator constructed a questionnaire comprising 38 statements and gave it to the second investigator for assessment. Of primary interest were whether the questionnaire indeed examined the areas under consideration and whether the important aspects in these areas were covered. The second investigator suggested changes in how the existing statements were formulated to make them clearer to the reader. He also suggested deleting statements that were repetitions of other statements and adding statements that had not been included. After that, seven of the statements were changed to inverse statements. In a second stage, the questionnaire was sent to three judges with experience in this field. They suggested very few changes, primarily small changes in how the existing statements were formulated.

The questionnaire has two parts (See Appendix 1): 
Part One examines the background variables of the principals (gender, education and seniority in teaching and administration, participation in in-service training on the topic of evaluating teacher performance). It also examines the details of the school, including size (number of students) and type (elementary, middle or high school).

Part Two consists of 40 statements that examine the principals' perceptions of teacher evaluation. The participants were asked to consider each statement and to circle the number expressing their degree of agreement, on a 4-point scale: 1 definitely do not agree; 2 - do not agree; 3 - agree; 4 - most certainly agree.

The hypothesis regarding the differences in principals' evaluations was examined by calculating averages and standard deviations and by using $\mathrm{t}$ and $\mathrm{F}$ tests to calculate significance levels. The reliability of the questionnaire was examined using the Cronbach's alpha coefficient.

The qualitative tools were open semi-structured interviews with school principals who had attended in-service training on the topic of evaluation (Sabar Ben-Yehoshua, 2001). In this type of interview, the major questions are formulated in advance but the order of their presentation is not predetermined, and questions can be added during the interview according to the context, with the interviewee's answers often leading to spontaneous questions.

Six general questions were put forward in the interviews:

1) How do you view the subject of teacher evaluation in your school?

2) Do you think it is proper for you to evaluate the teachers?

3) Do you see yourself as capable of evaluating the teachers in your school?

4) What barriers do you face in evaluating the teachers in your school?

5) Do you have any concerns regarding the evaluation of teachers?

6) Do you want to add anything else?

\subsection{Research Procedure}

The questionnaire was written and administered in Hebrew. The principals were asked to complete the questionnaire freely and accurately. In addition, it was made clear to all the participants that the questionnaire was anonymous and that the data would be used for research purposes only.

All the questionnaires were administered by the researchers. Of the 90 participating principals, 86 completed the questionnaire.

It should be noted that the two researchers are currently leading a process of training Arab principals on the topic of teacher evaluation in the Haifa District and the Northern District of the Ministry of Education. Thus, the research population was for the most part accessible to researchers and colleagues at the college, making the research easier to carry out.

\section{Data Analysis}

\subsection{Quantitative Findings}

The hypotheses were examined by analyzing the data using SPSS software. Averages, standard deviations and t-test values were calculated in order to determine the differences in principals' perceptions of teacher evaluation.

\subsection{Qualitative Findings}

Analyzing qualitative data involves a process of arranging and structuring the collected data in order to interpret and understand it (Shkedi, 2004). The analysis is based upon the subjective method, in which segments of text are analyzed rather than isolated words and expressions. The results of the analysis are subjective categories. According to this approach and to the research questions, the research identified major categories regarding the principals' perceptions of the topic of teacher evaluation.

\section{Findings}

Results for the first hypothesis: The first hypothesis was that the research findings would show that most of the principals perceive of teacher evaluation as transformational evaluation. In order to examine this hypothesis, we calculated the averages and frequencies of the principals' general perceptions of teacher evaluation. The average perception of teacher evaluation among the principals was 5.71, indicating that most of the principals perceived of teacher evaluation as more transformational than summative (Figure 1). 


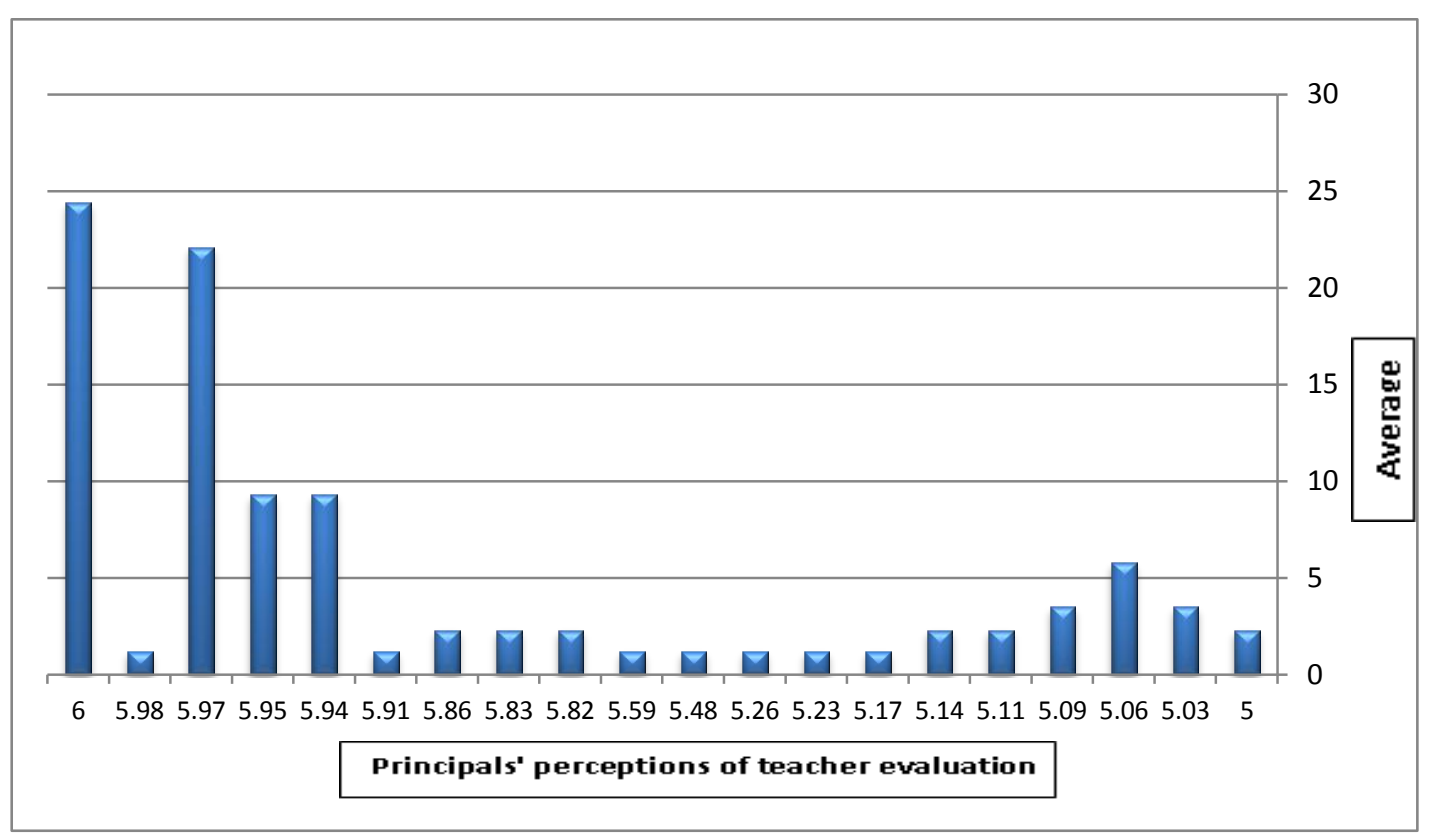

Figure 1. Average of principals' responses regarding their perception of teacher evaluation.

Results for the second hypothesis: The second research hypothesis was that principals' perceptions of teacher evaluation would differ between those who received in-service training on this topic and those who did not have such training. To examine the second research hypothesis, we conducted t-tests on independent samples (Table).

Table 3. Averages, standard deviations, $t$ values and significance levels for principals' perceptions of teacher evaluation, comparing those principals who underwent in-service training on the topic with those who did not $(\mathrm{N}=86)$.

\begin{tabular}{|c|c|c|c|c|c|c|}
\hline & \multicolumn{2}{|c|}{$\begin{array}{l}\text { Principals who underwent } \\
\text { in-service training } \\
\qquad \mathrm{N}=62\end{array}$} & \multicolumn{2}{|c|}{$\begin{array}{l}\text { Principals who did not } \\
\text { have in-service training } \\
\mathrm{N}=24\end{array}$} & \multirow[t]{2}{*}{$\begin{array}{c}\mathrm{T} \\
(23.74)\end{array}$} & \multirow[t]{2}{*}{$\begin{array}{c}\text { Significance } \\
\text { level }\end{array}$} \\
\hline & Average & SD & Average & $\mathrm{SD}$ & & \\
\hline $\begin{array}{l}\text { Principals' perception } \\
\text { of teacher evaluation }\end{array}$ & 5.96 & 0.04 & 5.18 & 0.24 & 15.67 & 0.00 \\
\hline
\end{tabular}
$* \mathrm{p}<0.001$

The results in the above table demonstrate significant differences between principals who underwent in-service training on the topic of teacher evaluation and those who did not, to the advantage of those who underwent the training: $\mathrm{t}(23.74)$ $=15.67, \mathrm{P}<0.001$. These findings corroborate the hypothesis and indicate that principals who underwent in-service training on the topic of teacher evaluation perceive of teacher evaluation as more transformational than do those who did not have this training (Figure 2).

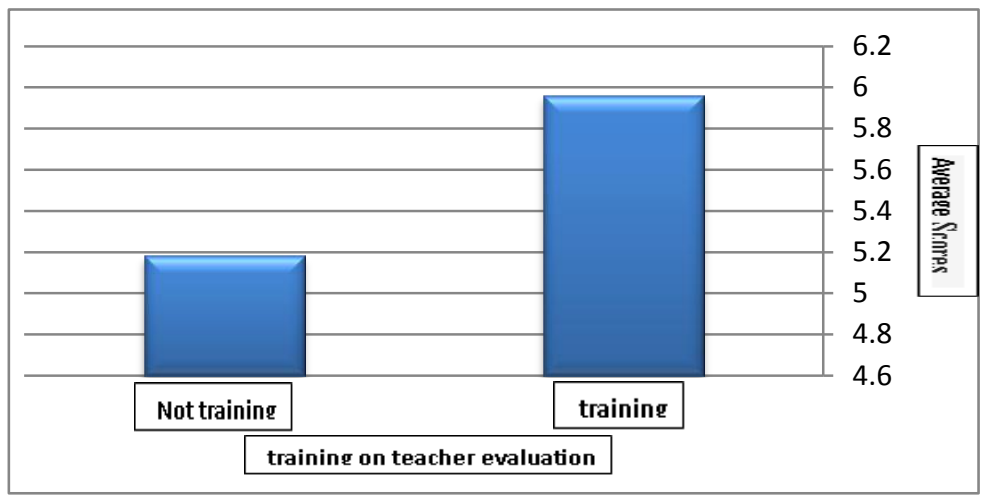

Figure 2. Principals' perceptions of teacher evaluation according to whether or not they attended in-service training on teacher evaluation. 
After t-tests were conducted on independent samples, no significant differences were found between males and females in their perceptions of teacher evaluation $\mathrm{t}(81)=.22, \mathrm{P}>0.05$. These results show that there are no significant statistical differences in principals' perceptions of teacher evaluation based upon gender (see table).

Table 4. Averages, standard deviations, $\mathrm{t}$ values and significance levels for principals' perceptions of teacher evaluation, comparing male and female principals $(\mathrm{N}=86)$.

\begin{tabular}{|c|c|c|c|c|c|c|c|}
\hline & \multicolumn{2}{|c|}{$\begin{array}{c}\text { Male } \\
\mathrm{N}=68 \\
\end{array}$} & \multicolumn{2}{|c|}{$\begin{array}{c}\text { Female } \\
\mathrm{N}=18\end{array}$} & \multirow[t]{2}{*}{$\mathbf{T}$} & \multirow[t]{2}{*}{ Value } & \multirow[t]{2}{*}{ Significance level } \\
\hline & Average & SD & Average & SD & & & \\
\hline Principals' perception of teacher evaluation & 5.75 & 0.37 & 5.73 & 0.38 & & 0.22 & $\mathbf{0 . 8 2}$ \\
\hline
\end{tabular}

A one-dimensional analysis of variance was conducted to examine the differences in perceptions of teacher evaluation among principals from different types of schools. The analysis did not reveal any statistically significant differences in principals' perceptions of teacher evaluation based on type of school, $\mathrm{F}(2,77)=0.36, \mathrm{P}>0.05$.

Table 5. Averages, standard deviations, $\mathrm{t}$ values and significance levels for principals' perceptions of teacher evaluation according to type of school $(\mathrm{N}=86)$.

\begin{tabular}{|c|c|c|c|c|c|c|c|c|}
\hline & \multicolumn{2}{|c|}{$\begin{array}{c}\text { Elementary } \\
\mathrm{N}=51\end{array}$} & \multicolumn{2}{|c|}{$\begin{array}{l}\text { Middle School } \\
\qquad \mathrm{N}=22\end{array}$} & \multicolumn{2}{|c|}{$\begin{array}{c}\text { High School } \\
\mathrm{N}=13 \\
\end{array}$} & \multirow{2}{*}{$\begin{array}{c}\text { F } \\
\text { Value }\end{array}$} & \multirow{2}{*}{$\begin{array}{c}\text { Significance } \\
\text { level }\end{array}$} \\
\hline & Average & SD & Average & SD & Average & SD & & \\
\hline $\begin{array}{l}\text { Principals' perception of teacher } \\
\text { evaluation }\end{array}$ & 5.74 & 0.37 & 5.77 & 0.37 & 5.84 & 0.26 & 0.36 & 0.69 \\
\hline
\end{tabular}

Most of the principals who underwent in-service training on the topic of teacher evaluation had a positive attitude toward evaluation and saw it as an impetus for improving teaching quality and promoting professionalism among the teachers. Those who did not undergo the training saw evaluation as problematic and as another burden placed on their work.

In summary, principals who underwent in-service training about teacher evaluation perceived of evaluation as a transformational and non-judgmental process whose goal was to help teachers improve their work while stressing the importance of the effect of compensation. Those principals who did not undergo the training perceived of evaluation as a means of exerting control, providing compensation and demonstrating a show of authority and relatively less as a form of transformational pedagogical leadership that uses evaluation to help teachers improve their teaching and to support their professional development.

After the findings were analyzed, we saw fit to carry out semi-structured interviews with ten of the principals who had undergone the in-service training on teacher evaluation. The objectives of these interviews were to see whether the training had brought the change in the perception of school principal the teachers' evaluation and to provide additional support for the significance of the findings. In the following sections we describe the qualitative findings.

The principals who underwent the in-service training saw the evaluation process as fair. According to them, the process emphasized their role as pedagogical leaders. Some of the principals were unsure where the evaluation process would lead and what the Ministry of Education would do with their evaluations. Most of the principals interviewed expressed their concerns about the next stage, in which they would have to evaluate veteran teachers.

\section{The principals noted various types of difficulties:}

Difficulties in the evaluation process itself: overemphasis on classroom observations, difficulties in observing individual lessons, problems in the teachers' self-evaluations, a sense of over load and repetition in using the evaluation tool.

Difficulties in providing feedback before and after the classroom observations: problems in conducting open, structured and transformational discussions. Some of the principals noted that "the discussions sometimes slide into arguments of I am right and you are wrong..." Teachers feel frustrated and helpless, and principals have trouble moving them from a closed and stubborn stance to a state of openness and flow.

Difficulties deriving from conditions and resources that are insufficient to carry out an optimal evaluation: One principal noted that "I am not sure it is possible for principals to implement their role as evaluator so long as they must also assume all the other burdens of their job as principal ..." 
Difficulties deriving from a lack of confidence regarding sufficient command of the knowledge required to be an evaluator. Some of the principals indicated that "I do not feel that I, in my role as principal, can assess the teacher's pedagogical level. I do not feel capable of evaluating teachers in certain disciplines." "The evaluation must include command of classroom management skills as well as command of the content, and I cannot do all of this on my own."

The principals expressed concerns about evaluating veteran teachers for promotion and about the ramifications of such evaluation on relations in the teachers' room. "When the implication is to give a promotion, this becomes very dirty business. The teachers will turn around and say, 'Why did you give me this evaluation and not that one?' This will not be pleasant. When someone from the outside did the evaluation, it was fine, but when the principal does it and must continue to work with the teachers on an ongoing basis, this can turn the school into an arena for disputes."

Almost all the principals who were interviewed expressed concerns about discussing the feedback both in the planning stage and after the observations. "Feedback discussions often made the teachers defensive and made me feel frustrated..." "Most of the feedback discussions took place in an uncomfortable and threatening atmosphere, which made it difficult for me to hold a transformational discussion. " "Feedback discussions make me anxious, particularly when I am talking to a teacher who is especially sensitive. I find myself beginning to filter what I say, and this makes me feel that the discussion is not genuine. "'I still find it difficult to give appropriate feedback. I need to practice finding the major problem, the focal points and the major issues of interest to me and to the teacher. The major advantage for me is that giving feedback has become a structured, organized and focused procedure." "Sometimes the feedback discussion does nothing to advance the teacher's learning, and is perceived as a waste of time." "During the feedback discussion I feel I have no control over what will develop. Negative things can suddenly come up and destroy the pleasant atmosphere I tried to build. Sometimes I am overcome by a sense of helplessness and this worries me and makes me feel anxious." "Sometimes I ask what the point of the discussion was. There is no answer to this, it's unclear, and that is bothersome. I don't know what to do. Should I have another discussion to try to fix things up? Will that help?"

Most of the principals were concerned and worried about the negative implications on both the individual and the school levels in the case of negative evaluations liable to lead to firing a teacher. "It is difficult and practically impossible to fire a veteran teacher who is frustrated and burnt out. There are many types of pressures - political pressures or those exerted by the extended family ('hamula') or by the teacher's colleagues. To fire a teacher, especially a veteran teacher, has implications at the school, in the community and even in the district, particularly if the teacher has connections." "This is a serious dilemma. On the one hand I am expected to be objective and to have good results, while on the other hand I'm under tremendous pressure that is difficult to withstand. I must be given the authority and the backing in order to evaluate teachers, and to fire unsuccessful teachers." "When I as principal give a teacher a low evaluation and when there is a major gap between my evaluation and the teacher's self-evaluation, this makes it difficult to be professional and objective. The teacher's emotions begin to emerge and so do mine, and this hinders the possibilities for learning and improvement."

Most of the principals noted the paradox between transformational evaluation and evaluation that leads to immediate material compensation. "According to Ministry of Education policy, the objectives of teacher evaluation are to improve teachers' teaching so as to promote students' learning and to increase teachers' motivation at work. The direct and immediate connection between the evaluation and monetary compensation turns the evaluation into compensatory evaluation and misses its declared targets." "There is an ethical conflict in the evaluation process, a conflict of values. On the one hand I must be professional and objective, while on the other hand I am not willing to fire a teacher who invested time and money in becoming a teacher. The teacher education colleges should block those who are not good teachers from entering the school system."

The principals expressed positive opinions of the in-service training they received on the topic of teacher evaluation. "The training influenced my perception of evaluation. In the past, the purpose of evaluation was to summarize the teacher's performance at the end of the year. Today a new dimension has been added: transformational evaluation with the purpose of improving the teacher's performance." "In the training I was exposed to new concepts regarding evaluation, such as reflection while planning, reflection during performance and reflection following performance." "I now can differentiate between evaluation as a culture whose objective is to improve, transform, guide, establish productive discussion and develop new means and methods of teaching and evaluation as a process whose objective is to summarize, examine, criticize, filter and investigate."

\section{Discussion}

Evaluating a large number of teachers in one year can place pressure on the entire system, and particularly on the principal. The evaluation should be spread over a relatively long period of time so that the process can mature and yield the maximum benefit. 
Principals that perceive of teacher evaluation as primarily summative and as a means of compensation without devoting any strategic or system-wide thought to it are likely to turn teacher evaluation into a technical matter that will place them under even more pressure. Principals have many demands on them that are much more pressing than evaluating teacher performance. Hence, teacher evaluation is liable to become a low priority, and even the teachers may see it as a burden. Under such circumstances the evaluation will miss its objective of transforming the system.

For teaching to be improved, teachers' performance in class must be evaluated systematically and meticulously. The principal must relate to teacher evaluation as an overall strategy and must integrate it into other steps taken to improve teaching and support teachers. Teacher evaluation will become effective only when it is transformed into a dynamic process that is partially informal and placed in the hands of the teaching staff. Focusing on learning evaluation is tantamount to focusing on the core of the educational enterprise. Hence, transformational evaluation must become part of the school culture in order to shift teacher evaluation from individual evaluation to strategic and system-wide thinking.

Is it possible for evaluation to bring about a profound change in a school's organizational culture and thus lead to a change in the learning atmosphere and experience at the school? A lack of correlation between the required change and the existing school culture is liable to lead to changes on the technical level only. According to Sarason (1982), change is only possible when the teacher evaluation process leads to changes in the two primary dimensions that are routinely found in most schools:

1) Programmatic regularities: class scheduling, recesses, test schedules, etc.

2) Behavioral regularities: The teacher's teaching behaviors and the students' learning behaviors in class (Sarason, 1982).

The impact of evaluation on the entire system will be diminished if the evaluation does not distinguish between high and low performance among teachers. A reality marked by al-musayarah $^{l}$ is liable to yield an evaluation that is more technical and formal (Arar, 2010) than a process that would have a positive impact on overall pedagogical processes in the school (Guterman, 2010).

Schools invest many resources in producing structured processes, computerized forms, organized procedures and the like, while investing less in how to carry out an evaluation and feedback discussion. Even when a principal does have such discussions with the declared objective of promoting the teacher, very few of these discussions manage to accomplish what they set out to do. Feedback is a major tool in management and in improving performance. Feedback that is amicable both to the principal and to the teacher will facilitate more open and constructive communication. This type of feedback can serve as an excellent basis for teacher evaluation.

In feedback discussions, principals have difficulty discussing gaps in performance with the teachers. They find such discussions unpleasant and therefore avoid them. Principals feel they have nothing new to contribute to veteran teachers, so the feedback is seen as a waste of time. They also sometimes believe that there is nothing to be improved and that everything is fine, or that they cannot have any impact because the teacher is older and "people do not change." The prevailing perception among the principals is that feedback is more for correcting mistakes and less as an opportunity for growth.

\section{Recommendations}

If the main task of the school principal as evaluator of teachers' work is related to the improvement of teaching and learning processes, the teachers as those who carry out these processes in practice must become major partners in the evaluation.

School principals must receive appropriate training to learn how to provide proper and amicable feedback. These skills must be practiced methodically by means of simulation. In this way the principals can experience the feedback, think together with the group and learn to provide more constructive feedback.

Organizational procedures for teacher evaluation must be maintained while at the same time establishing a culture of feedback that is transformational and empowering both for the teacher and for the principal. When the importance of feedback is assimilated, teachers will begin to ask for feedback because they will feel that such discussions can help them develop professionally.

\section{References}

Abu- Hussain, J., \& Gonen, S. (2013). Education for responsibility and responsibility for education. Mofet Institute and Al-Qasemi College of Education, Tel-Aviv (Hebrew).

\footnotetext{
${ }^{1}$ Al-musayarah is an Arabic term denoting the culturally prevalent code of behavior according to which the speaker does everything to avoid hurting or insulting the other.
} 
Abu-Saad, I. (2006). State-controlled education and identity formation among the Palestinian Arab minority in Israel. American Behavioral Scientist, 49(8), 1085-1100. http://dx.doi.org/10.1177/0002764205284720

Alpert, B. (2010). Incorporating qualitative data into quantitative research. In: Kasan, L. and Kremer Nevo, M. (eds.). Analysis methods of qualitative data. Ben Gurion University of the Negev (Hebrew).

Arar, K. (2010). Perception and use of teacher evaluation among elementary school principals in the Arab school system in Israel. Iyunin beminhal ubairgun hachinuch (Studies in educational administration and organization), 31, 325-349 (Hebrew).

Arar, K., \& Rigby, A. (2009). To participate or not to participate'-status and perception of physical education among Muslim Arab-Israeli secondary school pupils. Sport, Education and Society, 14(2), 183- 202. http://dx.doi.org/10.1080/13573320902809088

Bass, B. (1999). Two decades of research and development in transformational leadership. European journal of work and Organizational Psychology, 8, 9-32. http://dx.doi.org/10.1080/135943299398410

Beller, M., Hartaf, H., Ratner-Avrahami, O. (2011). Here it comes: A new model for teacher education. Hed Hachinuch, 86(2), 76-80 (Hebrew).

Cheng, Y. Ch. (1997). The Transformational Leadership for School Effectiveness and Development in the New Century. Paper read at International Symposium of Quality Training of Primary and Secondary Principals toward the 21 st Century, January 20-24, at Nanjing, China.

Coldren, A. F., \& Spillane, J. P. (2007). Making connections to teaching practice: The role of boundary practices in: instructional leadership Educational Policy, 21(2), 369-396. http://dx.doi.org/10.1177/0895904805284121

Conly, S., \& Glasman, N. (2008). Fear, the school organization, and teacher evaluation. Educational Policy, 22(1), 63-85. http://dx.doi.org/10.1177/0895904807311297

Daley, G., \& Kim, L. (2010). A teacher evaluation system that works. Institute for Excellence in teaching. Santa Monica: CA.

Danielson, S. (2001). New trends in Teacher Evaluation. Educational Leadership, 58(5), 12-15.

Darling-Hammond, L., Wise, A. E., \& Pease, S. R. (1983). Teacher evaluation in the organizational context: A review of the literature, Review of Educational Research, 3, 285-328. http://dx.doi.org/10.3102/00346543053003285

Fullan, M. (2001). Leading in a culture of change. San Francisco: Jossey-Bass.

Guterman, K. (2010). On the road to educational leadership: The next step, teaching observations and pedagogical discourse as the focus of the educational process and pedagogical growth in the school. In: Hahinuch Vesvivo (Education and Context): The Kibbutzim College of Education, Technology and Arts, 32, 149-167 (Hebrew).

Jabareen, Y., \& Agbaria, A. (2010). Education on hold: Government policies and citizen initiatives to promote Arab education in Israel. Haifa: Dirasat (Hebrew).

Kurland, H. (2010). Principals evaluate teachers: From perception to performance. Iyunin beminhal ubairgun hachinuch (Studies in educational administration and organization), 31, 271-323 (Hebrew).

Leithwood, K. (1997). Distributed Leadership in Secondary Schools. Paper read at Annual Meeting of the American Educational Research Association, March 24-28, Chicago, IL.

Leithwood, K., Day, C., Sammons, P., Harris, A., \& Hopkins, D. (2007). Seven strong claims about successful school leadership, Birmingham: NCSL.

Leithwood, K., Day, C., Sammons, P., Harris, A., \& Hopkins, D. (2006). Successful School Leadership: What it is and how it influences pupil learning. London: DfES.

Lewis, P., \& Murphy, R. (2008). Effective School leadership. National College for School Leadership. http://dx.doi.org/10.1080/13632430801969807

Marshall, K. (2005). It's time to rethink teacher supervision and evaluation, Phi Delta Kappa, 86(10), $727-736$.

McGhee, M.W., \& (2006). Sacrificing leaders, villainizing leadership: how educational accountability policies impair school leadership. Phi Delta Kappan, 86(5), 367-372.

Mckinsey \& Company. (2007). How the world's best-performing school systems come on top. City: Publisher.

Nasser-Abu Alhija F. (2010). Toward effective teacher evaluation. Hed Hachinuch, 88-90 (Hebrew).

Nevo, D. (2001). School Evaluation - Dialogue for Improving Schools. Reches Educational Projects Ltd. (Hebrew). 
Robbins, S. P. (2001). Organizational behavior, Prentice Hall, 9th edition.

Sabar Ben-Yehoshua, N. (2001). Genres and Traditions in Qualitative Research. Dvir: Tel Aviv (Hebrew).

Sarason, S. (1982). The Culture of School and the Problem of Change, Boston.

Sergiovanni, T. J. (2002). Theoretical and Practical Aspects of School Administration. Tel Aviv: The Open University (Hebrew).

Sergiovanni, T. J. (1990). Adding value to leadership gets extraordinary results, Educational leadership, 47, 23-27.

Shkedi, A. (2004). Words of Meaning: Qualitative Research - Theory and Practice. Tel Aviv: Ramot Publishers, Tel Aviv University (Hebrew).

Southworth, G. (2004). Primary School Leadership in Context: Leading small, medium and large sized schools. London: Routledge Falmer.

Southworth, G. (2009). Passionate work: towards a natural history of headship. In Davies \& Brighouse (Eds). The Essentials of School Leadership, London, Sage, $2^{\text {nd }}$ ed.

Stiggins, R., \& Duke, D. (2008). Effective instructional leadership requires assessment leadership, Phi Delta Kappa, 90, 285-291.

\section{Appendix 1}

\section{Questionnaire examining principals' perceptions of teacher evaluation in the school schools}

Dear Principal,

The following questionnaire is intended to examine principals' perceptions of teacher evaluation in the schools.

Please read the statements carefully and indicate what you believe and feel is your degree of agreement with each statement.

Thank you for your participation.

Part One: Personal Details
a. Gender:
1. Male 2. Female

b. Type of school where I am principal: 2. middle school 3. high school

1. elementary school

c. Teaching seniority (years):

d. Seniority as principal (years):

e. Education: 1. Teachers seminary

2. B.A. / B.Ed. degree

3. M.A. degree

4. $\mathrm{PhD}$. degree

f. Principals' course: 1. yes 2. no

g. Number of students at the school in the 2011-2012 school year:

h. This year a teacher evaluation process is taking place at the school where I am principal: 1 . yes 2. no

i. I received in-service training on the topic of teacher evaluation: 1 1. yes $\quad 2$. no

\section{Part Two}

Please examine the following statements. For each statement, circle the number representing the degree to which you agree with the statement on a scale from one to four:

1 - definitely do not agree; 2 - do not agree; 3 - agree; 4 - most certainly agree.

\begin{tabular}{|c|c|c|c|c|c|}
\hline \# & Statement & \multicolumn{4}{|c|}{$\begin{array}{l}\text { Degree of Agreement } \\
\text { with Statement }\end{array}$} \\
\hline 1 & Teacher evaluation helps teachers improve their students' learning. & 1 & 2 & 3 & 4 \\
\hline 2 & Teacher evaluation enables teachers to advance in professional rank. & 1 & 2 & 3 & 4 \\
\hline 3 & Teacher evaluation does not improve the teacher's teaching in the classroom. & 1 & 2 & 3 & 4 \\
\hline
\end{tabular}




\begin{tabular}{|c|c|c|c|c|c|}
\hline 4 & Teacher evaluation enables the teacher to rethink lesson planning. & 1 & 2 & 3 & 4 \\
\hline 5 & Teacher evaluation is a tool for principals to classify and screen teachers. & 1 & 2 & 3 & 4 \\
\hline 6 & Teacher evaluation does not enable teachers to participate in the evaluation process. & 1 & 2 & 3 & 4 \\
\hline 7 & $\begin{array}{l}\text { Teacher evaluation enables the principal to criticize teachers' work in the classroom } \\
\text { during lessons. }\end{array}$ & 1 & 2 & 3 & 4 \\
\hline 8 & Teacher evaluation enables the principal to support teachers. & 1 & 2 & 3 & 4 \\
\hline 9 & Teacher evaluation enables the principal to map out the tasks expected of the teacher. & 1 & 2 & 3 & 4 \\
\hline 10 & $\begin{array}{l}\text { Teacher evaluation enables the principal to help teachers adapt their teaching to } \\
\text { students with special needs. }\end{array}$ & 1 & 2 & 3 & 4 \\
\hline 11 & Teacher evaluation enables teachers to be more active in the school environment. & 1 & 2 & 3 & 4 \\
\hline 12 & Teacher evaluation does not help teachers improve learning among their students. & 1 & 2 & 3 & 4 \\
\hline 13 & $\begin{array}{l}\text { Teacher evaluation enables the principal to accumulate behavioral evidence regarding } \\
\text { how teachers function in all the areas they are expected to be involved in. }\end{array}$ & 1 & 2 & 3 & 4 \\
\hline 14 & Teacher evaluation enables the principal to monitor teacher improvement. & 1 & 2 & 3 & 4 \\
\hline 15 & $\begin{array}{l}\text { Teacher evaluation enables teachers to become more involved in their students' } \\
\text { learning processes. }\end{array}$ & 1 & 2 & 3 & 4 \\
\hline 16 & $\begin{array}{l}\text { Teacher evaluation constitutes a feedback tool for the teachers themselves regarding } \\
\text { their strong and weak points. }\end{array}$ & 1 & 2 & 3 & 4 \\
\hline 17 & Teacher evaluation facilitates cooperation between the principal and the teacher. & 1 & 2 & 3 & 4 \\
\hline 18 & Teacher evaluation causes student achievements to rise. & 1 & 2 & 3 & 4 \\
\hline 19 & Teacher evaluation does not allow teachers to enjoy the evaluation process. & 1 & 2 & 3 & 4 \\
\hline 20 & Teacher evaluation arouses resistance among the teachers. & 1 & 2 & 3 & 4 \\
\hline 21 & Teacher evaluation empowers the principal's pedagogic leadership. & 1 & 2 & 3 & 4 \\
\hline 22 & Teacher evaluation empowers the teachers. & 1 & 2 & 3 & 4 \\
\hline 23 & $\begin{array}{l}\text { Teacher evaluation facilitates the creation of an agreed-upon profile for teachers and } \\
\text { teaching in the school. }\end{array}$ & 1 & 2 & 3 & 4 \\
\hline 24 & $\begin{array}{l}\text { Teacher evaluation facilitates the creation of a common language of teaching quality } \\
\text { among the teaching staff }\end{array}$ & 1 & 2 & 3 & 4 \\
\hline 25 & $\begin{array}{l}\text { Teacher evaluation provides the principal a more in-depth understanding of the work } \\
\text { of the teachers. }\end{array}$ & 1 & 2 & 3 & 4 \\
\hline 26 & Teacher evaluation does not facilitate challenging activities for the teachers. & 1 & 2 & 3 & 4 \\
\hline 27 & $\begin{array}{l}\text { Teacher evaluation constitutes a tool for the principal to transfer teachers out of the } \\
\text { school. }\end{array}$ & 1 & 2 & 3 & 4 \\
\hline 28 & $\begin{array}{l}\text { Teacher evaluation does not help improve interpersonal relations among the school } \\
\text { staff. }\end{array}$ & 1 & 2 & 3 & 4 \\
\hline 29 & $\begin{array}{l}\text { Teacher evaluation is intended to motivate teachers to develop and improve their } \\
\text { performance. }\end{array}$ & 1 & 2 & 3 & 4 \\
\hline 30 & Teacher evaluation provides the principal ways of communicating with the teachers. & 1 & 2 & 3 & 4 \\
\hline 31 & Teacher evaluation enables teachers to invest more time in lesson planning. & 1 & 2 & 3 & 4 \\
\hline 32 & Teacher evaluation enables teachers to set personal goals for growth. & 1 & 2 & 3 & 4 \\
\hline 33 & $\begin{array}{l}\text { Teacher evaluation enables teachers to vary their teaching methods and ways of } \\
\text { evaluating their students. }\end{array}$ & 1 & 2 & 3 & 4 \\
\hline 34 & Teacher evaluation does not enable teachers to manage their teaching and learning. & 1 & 2 & 3 & 4 \\
\hline 35 & Teacher evaluation enables teachers to assess their own work. & 1 & 2 & 3 & 4 \\
\hline 36 & Teacher evaluation facilitates collaboration among the teaching staff. & 1 & 2 & 3 & 4 \\
\hline 37 & Teacher evaluation is intended to create a learning experience for the teachers. & 1 & 2 & 3 & 4 \\
\hline 38 & Teacher evaluation constitutes a tool for the principal to promote teachers. & 1 & 2 & 3 & 4 \\
\hline 39 & Teacher evaluation arouses motivation among the teachers. & 1 & 2 & 3 & 4 \\
\hline 40 & $\begin{array}{l}\text { Teacher evaluation constitutes a tool for the principal to determine teachers' salary } \\
\text { level and continued employment at the school. }\end{array}$ & 1 & 2 & 3 & 4 \\
\hline
\end{tabular}

\section{(c) $)$ EY}

This work is licensed under a Creative Commons Attribution 3.0 License. 